\title{
MONO-STARCH PHOSPHATE/MONTMORILLONITE NANOCOMPOSITES PREPARED BY VIBRATION MILLING: STRUCTURE AND ADSORPTION CAPACITY TOWARDS METHYLENE BLUE DYE
}

\author{
NATALIYA E. KOCHKINA* and NIKOLAY D. LUKIN** \\ ${ }^{*}$ G.A. Krestov Institute of Solution Chemistry of the Russian Academy of Sciences, \\ 1, Akademicheskaya Str., Ivanovo 153045, Russia \\ ***All-Russian Research Institute of Starch Products - Branch of V.M. Gorbatov Federal Research Center for \\ Food Systems of the Russian Academy of Sciences, 11, Nekrasova Str., \\ Kraskovo, Moskow Region 140051, Russia \\ \Corresponding author: Nataliya E. Kochkina, kochkinane@mail.ru
}

Received June 27, 2018

In the present work, for the first time, low-cost nanocomposites based on mono-starch phosphate (StPh) and montmorillonite (MMT) (1-5 wt\% based on dry $\mathrm{StPh}$ ) were prepared by a simple mechanical preparation method using a vibration mill. The structure and textural properties, as well as $\zeta$-potential of the $\mathrm{StPh} / \mathrm{MMT}$ nanocomposites, were characterized by X-ray diffraction, FTIR spectroscopy, low-temperature nitrogen adsorption/desorption and electrophoretic light scattering. The adsorption ability of the nanocomposites towards methylene blue dye was also evaluated. The obtained results demonstrated that the adsorption capacity of the $\mathrm{StPh} / \mathrm{MMT}$ nanocomposites increased with increasing MMT concentration. For all the nanocomposite samples, the adsorption kinetics and equilibrium adsorption isotherm were adequately described by the pseudo-second-order kinetic model and the Sips isotherm model, respectively. It was shown that the $\mathrm{pH}$ value for the nanocomposite containing $5 \mathrm{wt} \% \mathrm{MMT}$ had a minimal effect on the adsorption process efficiency. The recycling experiments demonstrated that the $\mathrm{StPh} / \mathrm{MMT}$ nanocomposite could be successfully used for MB removal after three adsorption cycles.

Keywords: mono-starch phosphate, montmorillonite, vibration mill, adsorption

\section{INTRODUCTION}

Adsorption is one of the most effective and widely used methods of industrial wastewater purification treatment, as it is accessible and environmentally benign. Different types of adsorbents are known to be applied in the adsorption process. ${ }^{1}$ Currently, there is a growing interest in adsorbents based on natural polysaccharides and their derivatives, which are cheap and eco-friendly materials, able to remove different pollutants, including textile dyes, heavy metals, herbicides, antibiotics. ${ }^{2}$

Starch has a special place among various natural polysaccharides. It is produced in huge quantities throughout the world and, owing to its unique physicochemical and functional properties, starch is extensively used in numerous applications, for instance, in foods, medicines, paper, textiles, oil industry etc. ${ }^{3}$ Native starches are characterized by weak adsorption ability towards wastewater pollutants because there are not enough highly active adsorbing groups in their structure. For the purpose of improving the adsorption capacity of native starch, various functional groups, including phosphate, cationic, carboxylate, amine, etc., are introduced in its backbone. ${ }^{4}$ As a rule, modified starches with a high degree of substitution are proposed as adsorbent materials. ${ }^{5,6}$ However, it should be noted that such a modification of starch can increase its cost and affect its toxicity and biodegradability. ${ }^{7}$

An effective strategy to address the problem of improving the adsorption ability of starch consists in the preparation of biopolymer/montmorillonite composite materials. Montmorillonite (MMT) is a well-known environmentally friendly and low cost filler for composites and nanocomposites. MMT is a smectite clay mineral, with a structure 
characterized by a three-layer package (2:1): two tetrahedral sheets covering an octahedral sheet on both sides. ${ }^{8}$ The external and internal surfaces of MMT are hydrophilic and polar, thus contributing to the intercalation of the polysaccharide macromolecules bearing polar groups, such as starch, cellulose, chitosan, proteins etc. into the interlayer space of the MMT. ${ }^{9}$ There are few works ${ }^{10-13}$ concerning the preparation of nanocomposites based on starch or modified starch for adsorption purposes. The authors of these papers reported the results of studying the sorption of textile dyes, ${ }^{10}$ hexavalent chromium ${ }^{11}$ and metal anions ${ }^{12}$ from aqueous solutions by cationic starch/MMT composite materials. Furthermore, Mahdavinia et al. ${ }^{13}$ described a method for producing starch-gpolyamidoxime/montmorillonite/ $/ \mathrm{Fe}_{3} \mathrm{O}_{4}$

nanocomposites, which were successfully applied for copper (II) ion removal from aqueous solutions.

The starch phosphate/MMT nanocomposite is another material that can be prepared and used as an adsorbent for wastewater purification treatment. The presence of phosphate groups in the starch macromolecules improves the biopolymer adsorption capacity. Previously, it was shown that cross-linked starch phosphates ${ }^{14,15}$ and cross-linked starch phosphate carbamate ${ }^{16}$ with a high degree of substitution demonstrated their ability to effectively adsorb divalent heavy metal ions. Up to now, there are no literature data on the use of composites based on MMT and mono-starch phosphate as cheap and non-toxic adsorbents for wastewater pollutants.

In the present work, novel materials based on mono-starch phosphate (StPh) and montmorillonite (MMT) were prepared by vibration milling. During the milling, a complex of mechanical actions (namely, shear, friction and collision) promoted MMT particle disintegration and $\mathrm{StPh}$ granules disruption, as well as intercalation of $\mathrm{StPh}$ macromolecules into the interlayer space of MMT. ${ }^{17,18}$ The key advantages of mechanical milling over other techniques commonly used for polymer/MMT nanocomposite preparation are: fewer technological stages, no need to use a solvent and high temperature treatment, environmental safety. Recently, we have successfully used vibration milling to obtain cationic starch/MMT adsorbent for acid dye removal. ${ }^{19}$ In this work, the $\mathrm{StPh} / \mathrm{MMT}$ nanocomposites prepared by milling have been characterized using FTIR spectroscopy, X-ray diffraction and low-temperature nitrogen adsorption-desorption methods. The effect of the MMT content on the zeta potential and the adsorption capacity of the nanocomposites towards cationic methylene blue have been evaluated.

\section{EXPERIMENTAL}

\section{Materials}

Methylene blue dye (MB) was obtained from CHIMMED Company (Moscow, Russia). StPh with the substitution degree of 0.02 was purchased from Dextrin Company Ltd. (Murom, Russia). The MMT particles were isolated according to the procedure described by Pokid'ko et al. $^{20}$ from bentonite clay, which was supplied by Bentonite Company Ltd. (Moscow, Russia). The MMT adsorption capacity towards $\mathrm{MB}$ was found to be $74 \mathrm{mg} / \mathrm{g}$. All the other chemicals employed in this study were of analytical grade. Distilled water was used in all the experiments.

\section{Preparation of StPh/MMT nanocomposites}

$\mathrm{StPh} / \mathrm{MMT}$ nanocomposites were prepared as follows. Firstly, $75 \mathrm{~g}$ of $\mathrm{StPh}$ was mixed manually with MMT particles (1, 3 and $5 \mathrm{wt} \%$ based on dry $\mathrm{StPh}$ ) dispersed in distilled water $(25 \mathrm{~mL})$ at room temperature $\left(25^{\circ} \mathrm{C}\right)$. Next, the blend of StPh and MMT was charged into a ceramic cylindrical vessel $(1 \mathrm{~L})$ packed with ceramic balls $(\varnothing 15 \mathrm{~mm}: \varnothing 10 \mathrm{~mm}=$ $3.5: 1$ ). The vessel was hermetically sealed and placed on the laboratory-made vibration mill (Fig. 1), where the mixture was milled for $1 \mathrm{~h}$. The volume ratio of balls/powder was 12:1. The activator vibration frequency was $50 \mathrm{~Hz}$, and the vibration amplitude was $1.6 \mathrm{~mm}$. The ceramic vessel was cooled to $20-25{ }^{\circ} \mathrm{C}$ throughout the milling process by the air cooling system to avoid sample overheating. After the milling, the composite with milling balls was discharged from the milling vessel onto a sieve with the mesh size of 2 $\mathrm{mm}$. Sieving was carried out for 10 minutes, using a "Vibrotekhnic" vibratory sieve shaker (Russia) in order to achieve separation of the composite powder.

\section{X-ray diffractometry (XRD)}

XRD analysis of the samples was performed using a Bruker D8 Advance X-ray diffractometer (BrukerAXS, Germany). The data were collected in the range of $2 \Theta=3-10^{\circ}$ with a step size of $0.01^{\circ}$.

\section{FTIR spectroscopy}

IR spectra of the samples under study were recorded at room temperature, using an Avatar ESP 360 Fourier transform IR spectrophotometer (Nicolet, USA) in the wavenumber range of $400-4000 \mathrm{~cm}^{-1}$ with a resolution of $2 \mathrm{~cm}^{-1}$ and averaging over 64 scans. 


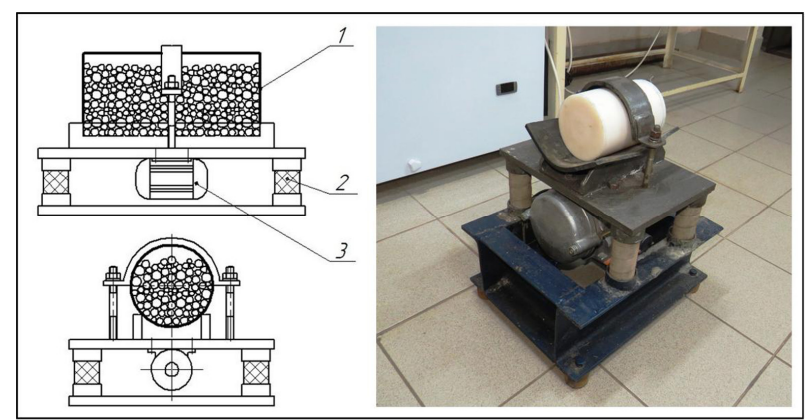

Figure 1: Laboratory-made vibration mill scheme: 1) ceramic cylindrical vessel, 2) vibration spring mounting, and 3) electromechanical oscillator

\section{Low-nitrogen adsorption/desorption}

Porosimetric measurements of the samples were carried out by low-temperature nitrogen adsorption/desorption, using a Nova 1200 Series (Quantachrome, USA). Prior to the measurements, the samples were degassed at $80{ }^{\circ} \mathrm{C}$ and the residual pressure of 5-10 Pa for $3 \mathrm{~h}$.

\section{Zeta potential determination}

Zeta potential values were measured by the electrophoretic light scattering method, using a Zetasizer Nano ZS analyzer (Malvern, UK). For this purpose, $\mathrm{StPh}$ and $\mathrm{StPh} / \mathrm{MMT}$ dispersions (0.5 wt\%) were prepared in a $0.1 \mathrm{M} \mathrm{NaCl}$ solution. The initial $\mathrm{pH}$ of the $\mathrm{NaCl}$ solution was adjusted with a $0.01 \mathrm{M} \mathrm{HCl}$ or a $0.01 \mathrm{M} \mathrm{NaOH}$ solution. The dispersions were shaken for $24 \mathrm{~h}$ before the zeta potential determination. All the measurements were repeated three times.

\section{Adsorption experiments}

The kinetic study of the adsorption ability of the samples under study was carried out using an MB aqueous solution of $20 \mathrm{mg} \mathrm{L}^{-1}$ at the temperature of 25 ${ }^{\circ} \mathrm{C}$. In each experiment, $25 \mathrm{~mL}$ of the dye solution was added to $0.025 \mathrm{~g}$ of the adsorbent in a cone flask and stirred continuously for a given contact time. The $\mathrm{pH}$ value of the reaction mixtures was 7.1. Then, the MB solution was separated by centrifugation at $10000 \mathrm{rpm}$ for $15 \mathrm{~min}$. The residual dye concentration in the supernatant was determined with a Libra S4 spectrophotometer (Biochrom Ltd., UK) by measuring the absorbance at $664 \mathrm{~nm}$. The amount of the adsorbed dye $Q_{t}(\mathrm{mg} / \mathrm{g})$ onto the sample was calculated by Equation (1):

$Q_{t}=\frac{C_{0}-C_{t}}{m} V$

where $C_{0}$ and $C_{t}\left(\mathrm{mg} \mathrm{L}^{-1}\right)$ are the initial concentration of the MB solution and the dye concentration at time $t$ (min), respectively, and $V$ is the volume of the dye solution (L).

The adsorption isotherms were determined using MB solutions with the initial concentration between 2 and $20 \mathrm{mg} \mathrm{L}^{-1}$. The effect of the solution $\mathrm{pH}$ on the amount of adsorbed $\mathrm{MB}$ dye was evaluated by varying the $\mathrm{pH}$ of the $\mathrm{MB}$ solutions using a $0.01 \mathrm{M} \mathrm{HCl}$ or a $0.01 \mathrm{M} \mathrm{NaOH}$ solution.

The adsorption experiments were repeated three times and the average of the data (the standard error was $\pm 3-5 \%$ ) was used to build the resultant plots.

\section{RESULTS AND DISCUSSION $\mathrm{X}$-ray diffraction analysis}

It is known that the evidence for the formation of a nanocomposite based on polymer and MMT is the increase in the distance between the silicate layers as a result of the macromolecule intercalation into the interlayer space of the MMT. ${ }^{9}$ Figure 2 demonstrates small-angle diffractograms for the initial MMT and $\mathrm{StPh} / \mathrm{MMT}$ samples. As can be seen, the MMT showed a characteristic diffraction peak at $2 \theta=$ $6.9^{\circ}$, corresponding to the basal distance $d_{001}=$ $1.27 \mathrm{~nm}$ and the interlayer distance $D=1.27-0.95$ $=0.32 \mathrm{~nm}$, where $0.95 \mathrm{~nm}$ is the thickness of the individual silicate layer of the MMT. ${ }^{21}$ In the case of the $\mathrm{StPh} / \mathrm{MMT}$ samples, there was a shift of the diffraction peak position in the direction of small angles, namely, the basal distance $d_{001}$ and the interlayer distance $D$ increased up to values of $1.85 \mathrm{~nm}$ and $0.90 \mathrm{~nm}$, respectively. This fact indicated that the biopolymer chains could penetrate into the interlayer space of the MMT and, consequently, nanocomposites were formed.

\section{FTIR analysis}

Details of the interaction between the $\mathrm{StPh}$ and MMT in the nanocomposite samples were revealed by the FTIR spectroscopy analysis (Fig. 3 ). The IR spectrum of the initial MMT showed a characteristic vibration peak at $3629 \mathrm{~cm}^{-1}$, which was attributed to the $\mathrm{Me}-\mathrm{O}-\mathrm{H}(\mathrm{Me}=\mathrm{Si}, \mathrm{Mg}$ or Al) bonds. ${ }^{22}$

The broad adsorption band near $3430 \mathrm{~cm}^{-1}$ corresponded to the $\mathrm{H}-\mathrm{O}-\mathrm{H}$ stretching vibrations of the interlayer/adsorbed water. The strong band 
centered at $1038 \mathrm{~cm}^{-1}$ and at $802 \mathrm{~cm}^{-1}$ could be attributed to the $\mathrm{Si}-\mathrm{O}$ stretching vibrations of the tetrahedral sheet. Furthermore, there were bands of bridging $\mathrm{Si}-\mathrm{O}-\mathrm{Al}$ bonds $\left(520 \mathrm{~cm}^{-1}\right)$ and $\mathrm{Si}-\mathrm{O}-$ Si bending vibrations $\left(465 \mathrm{~cm}^{-1}\right) .^{23}$

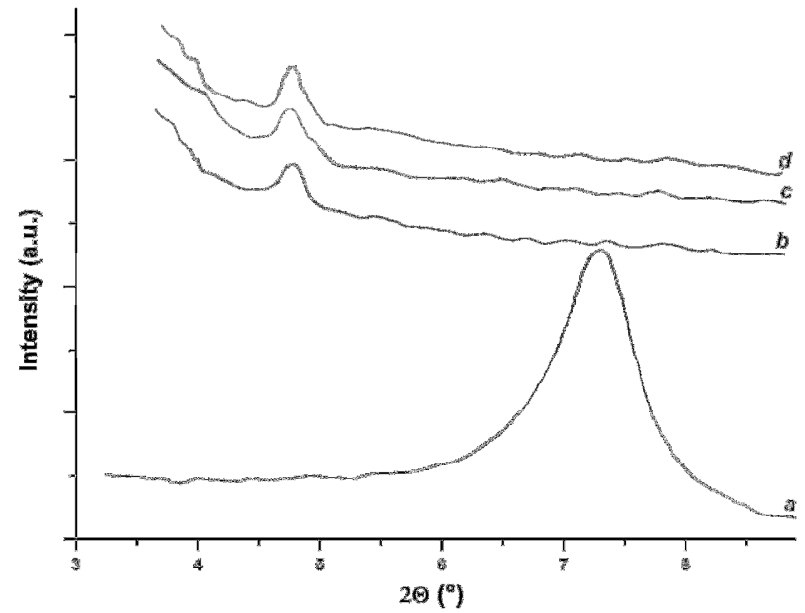

Figure 2: X-ray diffraction patterns for MMT (a) and nanocomposites containing $1 \mathrm{wt} \%$ (b), 3 wt\% (c) and $5 \mathrm{wt} \%$ (d) MMT

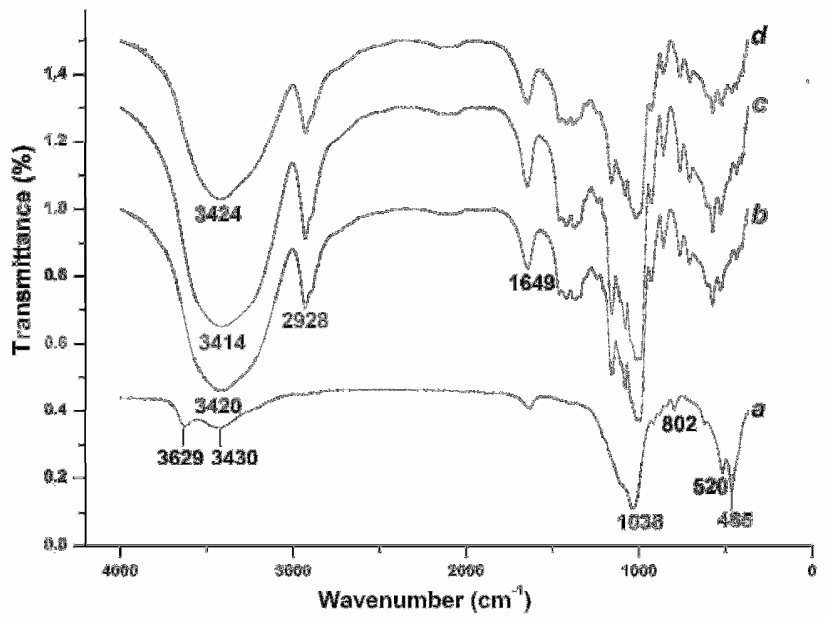

Figure 3: FTIR spectra of MMT (a), StPh (b), milled StPh (c) and nanocomposite containing 5 wt\% MMT (d)

The spectrum of the pure $\mathrm{StPh}$ exhibited characteristic bands of this biopolymer. ${ }^{24}$ The typical broad band with the maximum at $3420 \mathrm{~cm}^{-}$ ${ }^{1}$ was assigned to the $\mathrm{O}-\mathrm{H}$ groups involved in the formation of inter- and intramolecular hydrogen bonds. The bands at $2928 \mathrm{~cm}^{-1}$ and at $1157 \mathrm{~cm}^{-1}$ were associated with the stretching vibrations of $\mathrm{CH}_{2}$ groups and the antisymmetric stretching vibrations of the bridging $\mathrm{C}-\mathrm{O}-\mathrm{C}$ bonds, respectively. The band at $1649 \mathrm{~cm}^{-1}$ resulted from vibrations of adsorbed water molecules. The set of bands in the range of $500-1100 \mathrm{~cm}^{-1}$ could be attributed to the vibrations of D-glucopyranose ring and the $\mathrm{C}-\mathrm{O}$ bond in the glycosidic linkages. As known, the evidence for the starch phosphorylation could be the presence of the band between 1150 and $1185 \mathrm{~cm}^{-1}$ attributed to the $\mathrm{P}=\mathrm{O}$ stretching and the band at $1055-950 \mathrm{~cm}^{-1}$ assigned to the C-O-P bond of the phosphate group. ${ }^{25}$ However, for the sample under study, these bands overlapped with the aforementioned ones from the $\mathrm{StPh}$ backbone, which made it difficult to identify phosphate ester groups by FTIR analysis.

The milling treatment of the $\mathrm{StPh}$ did not result in the appearance of new bands in the FTIR 
spectrum of the sample. At the same time, for the mild $\mathrm{StPh}$, the band at $3420 \mathrm{~cm}^{-1}$ from hydrogen bonds shifted to lower frequency. The most likely reason for this effect was the decrease in the hydrogen bond number in the sample crystalline phase, resulting in an increase in the free $\mathrm{OH}$ groups in the amorphous phase.

The spectrum of the $\mathrm{StPh} / \mathrm{MMT}$ nanocomposite exhibited the bands of its components. In addition, one could note the disappearance of the band at $3629 \mathrm{~cm}^{-1}$ from $\mathrm{O}-\mathrm{H}$ group of MMT surface and a shift of the band at $3414 \mathrm{~cm}^{-1}$ from the hydrogen bonds of the milled $\mathrm{StPh}$ to higher values. These facts pointed to the interaction between the StPh and MMT and could be associated with hydrogen bond formation between the oxygen-containing groups of the starch ester and the hydroxyl groups of MMT.

\section{Analysis of textural properties}

The results of studying the textural characteristics of the $\mathrm{StPh}$ and $\mathrm{StPh} / \mathrm{MMT}$ nanocomposites by low-temperature nitrogen adsorption/desorption are shown in Table 1. It can be noted that the pure StPh had low values of the specific surface area $\left(S_{\mathrm{BET}}\right)$ and pore volume $\left(V_{\text {total }}\right)$, and the vibration milling had almost no influence on these parameters. As a result of $\mathrm{StPh}$ and MMT combination, materials with higher $S_{\text {BET }}$ and $V_{\text {total }}$ values were formed. The improved textural properties could provide an enhanced adsorption capacity of the nanocomposites.

\section{Measurement of zeta potential}

Zeta potential $(\zeta-$ potential) is an important parameter providing information on the charge state of particle surfaces, which could essentially influence the adsorption process. The value of this parameter is often used as a measure of attractive/repulsive electrostatic interaction forces between particles in a suspension. The dependence of the $\zeta$ - potential of the StPh samples and the nanocomposites on $\mathrm{pH}$ is shown in Figure 4. The StPh exhibited low negative values of the $\zeta$ - potential over the entire $\mathrm{pH}$ range due to the anionic groups located on the surface of the particles.

Table 1

Porosimetry data for the adsorbent samples

\begin{tabular}{lccc}
\hline Sample & $S_{\text {BET }}\left(\mathrm{m}^{2} / \mathrm{g}\right)$ & $V_{\text {total }}\left(\mathrm{cm}^{3} / \mathrm{g}\right) \times 10^{-3}$ & $D_{\mathrm{p}}(\mathrm{nm})$ \\
\hline SPh & 0.678 & 0.681 & 4.02 \\
SPh milled & 0.723 & 0.998 & 4.58 \\
SPh/MMT 1\% & 1.037 & 1.003 & 4.53 \\
SPh/MMT 3\% & 1.371 & 1.506 & 4.95 \\
SPh/MMT 5\% & 3.516 & 4.027 & 5.50 \\
\hline
\end{tabular}

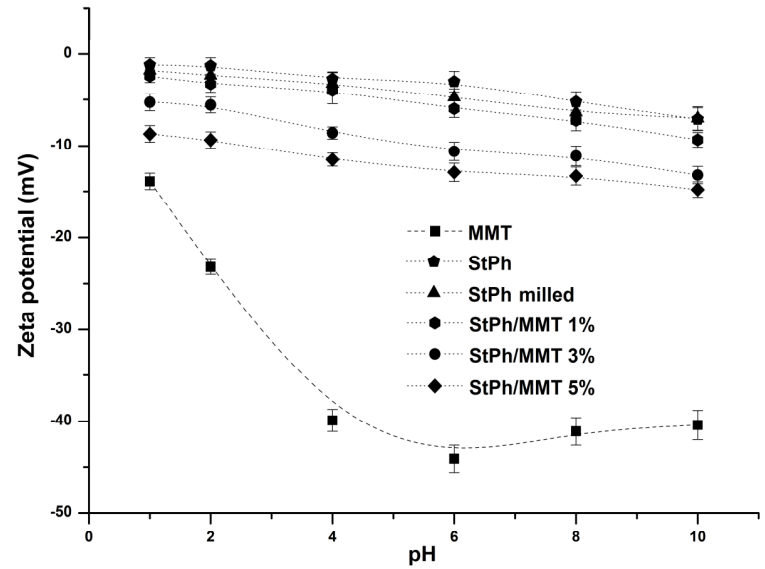

Figure 4: Zeta potential as a function of $\mathrm{pH}$ values for the adsorbent samples tested in this work

One can note that the mechanical treatment in the vibration mill had a negligible impact on this characteristic of the sample. The MMT particles also demonstrated negative values of the $\zeta$ - 
potential, confirming the anionic surface charge of their surface. In the low $\mathrm{pH}$ range, the MMT zeta potential became less negative, owing to the partial neutralization of the charge by the acid solution protons. The $\mathrm{StPh}$ matrix filling with MMT particles resulted in an essential decrease in the $\zeta$ - potential value, as compared with pure $\mathrm{StPh}$, and this can have a positive effect on the cationic dye adsorption.

\section{Adsorption kinetics}

Adsorption kinetics is a very important characteristic in defining the efficiency and practical application of adsorbents. Kinetics analysis provides information about the possible adsorption mechanism, as well as the factors affecting this process. The influence of time on the adsorption of methylene blue dye by the adsorbents under study is shown in Figure 5. As can be seen in the initial stage of the dye adsorption by $\mathrm{StPh}$ particles, there was a rapid decrease in the dye concentration in the solution. After 10 minutes of contact between the adsorbent and the dye solution, the adsorption process became slower and adsorption equilibrium was reached in about 30 minutes. The high rate of dye removal from the solution in the initial period of the adsorption pointed to sterically advantageous positions of the active adsorption centers on the adsorbent surface.

The main difference between the adsorbents under study was in the amount of the dye adsorbed after reaching the adsorption equilibrium. One can note that the vibration milling of the $\mathrm{StPh}$ increased its $Q t$ value. Based on the results of the works that studied the adsorption properties of $\mathrm{StPh},{ }^{15,16}$ it could be supposed that the possible adsorption mechanism under study may be the ionic interaction of the cationic dye ions with the phosphate groups. Besides, hydrogen bonds can also be formed between the biopolymer hydroxyl groups and the dye molecules. Therefore, the revealed increase in the milled StPh $Q t$ value was perhaps due to the aforementioned increment of the free $\mathrm{OH}$ groups in the adsorbent structure, which could participate in hydrogen bond formation with the methylene blue dye molecules, thereby enhancing the adsorption process. The nanocomposite with $1 \%$ MMT demonstrated a 1.5 time $Q t$ value increase, compared to pure $\mathrm{StPh}$. The increase in the MMT concentration in the nanocomposite up to $5 \mathrm{wt} \%$ was accompanied by a three-time $Q t$ growth. The experimental maximum amounts of the dye adsorbed at equilibrium $Q_{\max }$ were found to be 6.84, 8.29, 9.96, 16.35 and $19.26 \mathrm{mg} / \mathrm{g}$ for $\mathrm{StPh}$, $\mathrm{StPh}$ milled, StPh/MMT 1\%, StPh/MMT 3\% and $\mathrm{StPh} / \mathrm{MMT}$ 5\% adsorbents, respectively. The most likely reasons for the increased adsorption capacity of the nanocomposites were the more negative value of $\zeta$ - potential and the increased specific surface area of their particles.

To evaluate the adsorption mechanism, the experimental data were approximated by the wellknown kinetic models, ${ }^{26,27}$ namely:

Lagergren (pseudo-first order):

$Q_{t}=Q_{e}\left(1-\exp ^{-k_{1} t}\right)$

Ho and McKay (pseudo-second order):

$Q_{t}=\frac{k_{2} Q_{e}^{2} t}{1+k_{2} Q_{e} t}$

where $Q_{e}$ and $Q_{t}$ are the amounts of the dye adsorbed at equilibrium and at time $t\left(\mathrm{mg} \mathrm{g}^{-1}\right)$, respectively; $k_{1}$ and $k_{2}$ are the pseudo-first order rate constant $\left(\mathrm{min}^{-1}\right)$ and the equilibrium rate constant of pseudo-second order $\left(\mathrm{g} \mathrm{mg}^{-1} \mathrm{~min}^{-1}\right) ; t$ is the contact time ( $\mathrm{min}$ ).

The model parameters obtained by the nonlinear least square optimization technique, which was applied for fitting of the adsorption kinetics data, are given in Table 2 . The criteria for the adequacy of the models were the determination coefficient $\mathrm{R}^{2}$ and the Chi-square $\left(\chi^{2}\right)$ test. The $\chi^{2}$ test is represented mathematically as follows:

$\chi^{2}=\sum \frac{\left(Q_{\text {exp }}-Q_{\text {mod }}\right)^{2}}{Q_{\text {mod }}}$

where $Q_{\exp }$ and $Q_{\text {mod }}(\mathrm{mg} / \mathrm{g})$ are the experimental value and the model calculation value of adsorption capacity, respectively. A smaller $\chi^{2}$ value indicated a better fitting model.

As can be seen, for the $\mathrm{StPh}$ and all the nanocomposite samples, the pseudo-second order chemisorption kinetic model gave the highest $R^{2}$ values and the lowest $\chi^{2}$ values, thereby showing that the adsorption process was significantly affected by chemisorption. At the same time, the high $\mathrm{R}^{2}$ values for the pseudo-first order kinetic model indicated that the film diffusion process also contributed to the methylene blue adsorption by the samples under study. The process of adsorption for the dye on the samples is likely to include both physical and chemical sorption. 


\section{Adsorption equilibrium}

The adsorption isotherms are commonly used to identify the peculiarities of interaction between adsorbate and adsorbent particles. Figure 6 presents the isotherms of methylene blue dye adsorption on the adsorbent samples under study.

One can note that the isotherm curves for the $\mathrm{StPh}$ samples and nanocomposite samples had different shapes. The isotherms for the $\mathrm{StPh} / \mathrm{MMT}$ nanocomposites grew much more strongly at a low dye concentration and the equilibrium concentrations for the nanocomposite samples were high compared to those of the $\mathrm{StPh}$ samples, indicating a considerably better affinity of the nanocomposite materials for the dye. The $Q_{\max }$ values determined from this experiment were found to be $6.13,7.07,12.47,15.73$ and 29.70 $\mathrm{mg} / \mathrm{g}$ for $\mathrm{StPh}, \mathrm{StPh}$ milled, StPh/MMT $1 \%$, $\mathrm{StPh} / \mathrm{MMT} 3 \%$ and StPh/MMT 5\% adsorbents, respectively.
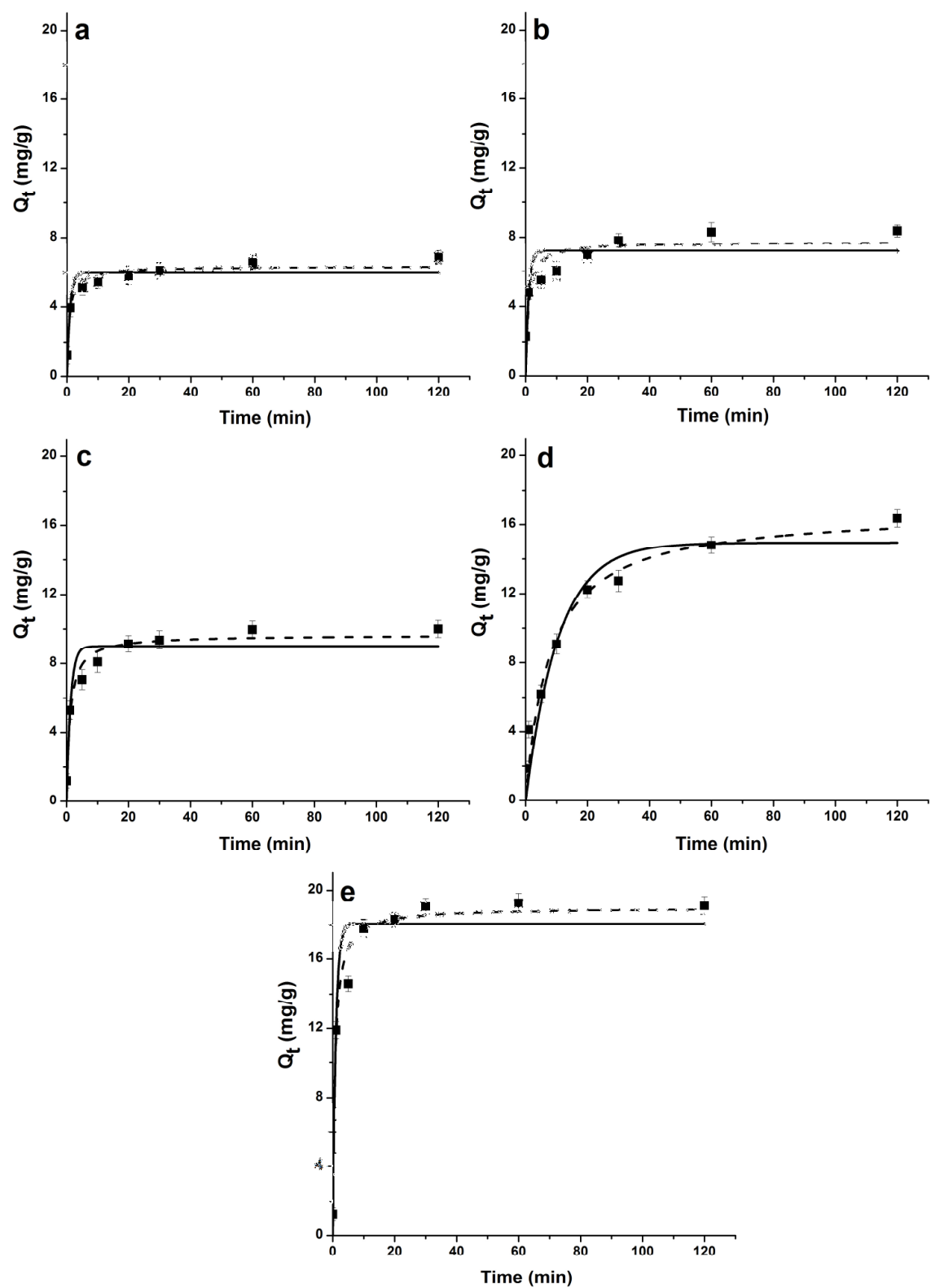

Figure 5: Kinetic sorption curves of $\mathrm{MB}$ dye onto $\mathrm{StPh}(\mathrm{a})$, milled $\mathrm{StPh}$ (b) and nanocomposites containing 1 wt\% (c), 3 $\mathrm{wt} \%$ (d) and $5 \mathrm{wt} \%$ (e) MMT (the symbols represent the experimental values, and the lines show the calculated kinetics using the pseudo-first order (-) and the pseudo-second order (---) models) 
Table 2

Parameters of methylene blue dye adsorption kinetics for the prepared adsorbents

\begin{tabular}{|c|c|c|c|c|c|}
\hline Kinetic model & $\mathrm{StPh}$ & $\begin{array}{l}\text { StPh } \\
\text { milled }\end{array}$ & $\begin{array}{c}\mathrm{StPh} / \\
\text { MMT 1\% }\end{array}$ & $\begin{array}{c}\text { StPh/ } \\
\text { MMT 3\% }\end{array}$ & $\begin{array}{c}\mathrm{StPh} / \\
\mathrm{MMT} 5 \%\end{array}$ \\
\hline \multicolumn{6}{|l|}{ Pseudo-first order } \\
\hline $\mathrm{Q}_{\mathrm{e}}\left(\mathrm{mg} \mathrm{g}^{-1}\right)$ & 6.009 & 7.192 & 9.007 & 14.956 & 18.066 \\
\hline $\mathrm{k}_{1}\left(\min ^{-1}\right)$ & 1.044 & 1.056 & 0.779 & 0.094 & 1.032 \\
\hline $\mathrm{R}^{2}$ & 0.829 & 0.520 & 0.861 & 0.906 & 0.928 \\
\hline$\chi^{2}$ & 0.570 & 2.032 & 1.261 & 2.556 & 2.743 \\
\hline \multicolumn{6}{|c|}{ Pseudo-second order } \\
\hline $\mathrm{Q}_{\mathrm{e}}\left(\mathrm{mg} \mathrm{g}^{-1}\right)$ & 6.322 & 7.706 & 9.656 & 16.811 & 18.974 \\
\hline $\mathrm{k}_{2}\left(\mathrm{~g} \mathrm{mg}^{-1} \min ^{-1}\right)$ & 0.218 & 0.142 & 0.094 & 0.007 & 0.074 \\
\hline $\mathrm{R}^{2}$ & 0.884 & 0.645 & 0.937 & 0.943 & 0.970 \\
\hline$\chi^{2}$ & 0.384 & 1.522 & 0.567 & 1.543 & 1.128 \\
\hline
\end{tabular}

In this study, two-parameter models (Langmuir and Freundlich) ${ }^{28}$ and a threeparameter model (Sips) ${ }^{29}$ were used to describe the adsorption isotherms. The Langmuir model assumes that adsorption is a reversible process and it is restricted to a monolayer in the adsorbent. Adsorption takes place only at specific sites of the adsorbent; all the adsorption sites are energetically equivalent and each of the sites can adsorb only one molecule of the adsorbate. The Freundlich isotherm is an empirical model, which suggests that the adsorption occurs on the heterogeneous surface of the particles and it is not limited to monolayer formation. The Sips model is a combination of the Langmuir and the Freundlich models and it can model the adsorption process on both homogeneous and heterogeneous surfaces.

The isotherm models are represented by the following equations:

Freundlich: $Q_{e}=K_{F} C_{e}^{1 / n}$

Langmuir: $Q_{e}=\frac{k_{L} C_{e}}{1+a_{L} C_{e}}$

Sips: $Q_{e}=\frac{Q_{m} K_{S} C_{e}^{1 / n}}{1+K_{S} C_{e}^{1 / n}}$

where $C_{\mathrm{e}}\left(\mathrm{mg} \mathrm{L}^{-1}\right)$ and $Q_{\mathrm{e}}\left(\mathrm{mg} \mathrm{g}^{-1}\right)$ are the liquid phase concentration and the solid phase concentration of an adsorbate at equilibrium, respectively; $K_{F}$ is the Freundlich constant (mg g$\left.{ }^{1}\right)$ and $1 / n$ is the heterogeneity factor; $k_{\mathrm{L}}\left(\mathrm{L} \mathrm{g}^{-1}\right)$ and $a_{\mathrm{L}}\left(\mathrm{L} \mathrm{mg}^{-1}\right)$ are the Langmuir isotherm constants; $Q_{m}\left(\mathrm{mg} \mathrm{g}^{-1}\right)$ is the quantity of the dye adsorbed at saturation or the monolayer capacity and $K_{S}\left(\mathrm{~L} \mathrm{mg}^{-1}\right)$ is the Sips constant.

The adsorption parameters and the corresponding correlation coefficients are shown in Table 3. According to the $\mathrm{R}^{2}$ values, the Freundlich model described methylene blue dye adsorption more adequately in the case of the original $\mathrm{StPh}$ and milled $\mathrm{StPh}$ adsorbent, whereas for the nanocomposites, the Sips model was more suitable. Thus, one can conclude that all the adsorbents were characterized by heterogeneous distribution of the active adsorption sites and the process of adsorption onto the nanocomposite particles corresponded to the monolayer coverage of the dye. The calculated maximum adsorption capacity of the examined samples clearly demonstrated the advantages of $\mathrm{StPh} / \mathrm{MMT}$ nanocomposites in cationic dye removal.

\section{Effect of pH}

It is well-known that the $\mathrm{pH}$ of the methylene blue solution has a significant effect on the mechanism of the dye adsorption and therefore on the removal efficiency. In the present study, the effect of $\mathrm{pH}$ on the methylene blue adsorption was studied at the contact time of 40 minutes and the temperature of $25^{\circ} \mathrm{C}$. The results are shown in Figure 7. An increase in the $\mathrm{pH}$ value was accompanied by a decrease in the $\zeta$ - potential value of the $\mathrm{StPh}$ samples and, hence, an increment of their adsorption ability was observed. An important positive feature of the nanocomposites as adsorbents was that their adsorption capacity was less dependent on the $\mathrm{pH}$ value and this characteristic was particularly pronounced for the samples with $5 \mathrm{wt} \%$ MMT. The surface of nanocomposite particles had a rather strong negative charge and the dye molecules were positively charged in the $\mathrm{pH}$ range of 2-10, so electrostatic interactions between the adsorbents and dye molecules could be established. At the same time, the fact that, for 
the $\mathrm{StPh} / \mathrm{MMT5}$ sample, the decrease in the zeta potential value with a $\mathrm{pH}$ value increase does not result in a significant increase in the adsorption capacity indicates that the adsorption process is not dependent on electrostatic interactions only. It is likely that the specific features of adsorption of
MB molecules characterized by the formation of associates (dimers, trimers etc.) in the solution ${ }^{30}$ are mainly determined by the porous structure of the nanocomposite sample rather than by the charge of its surface.
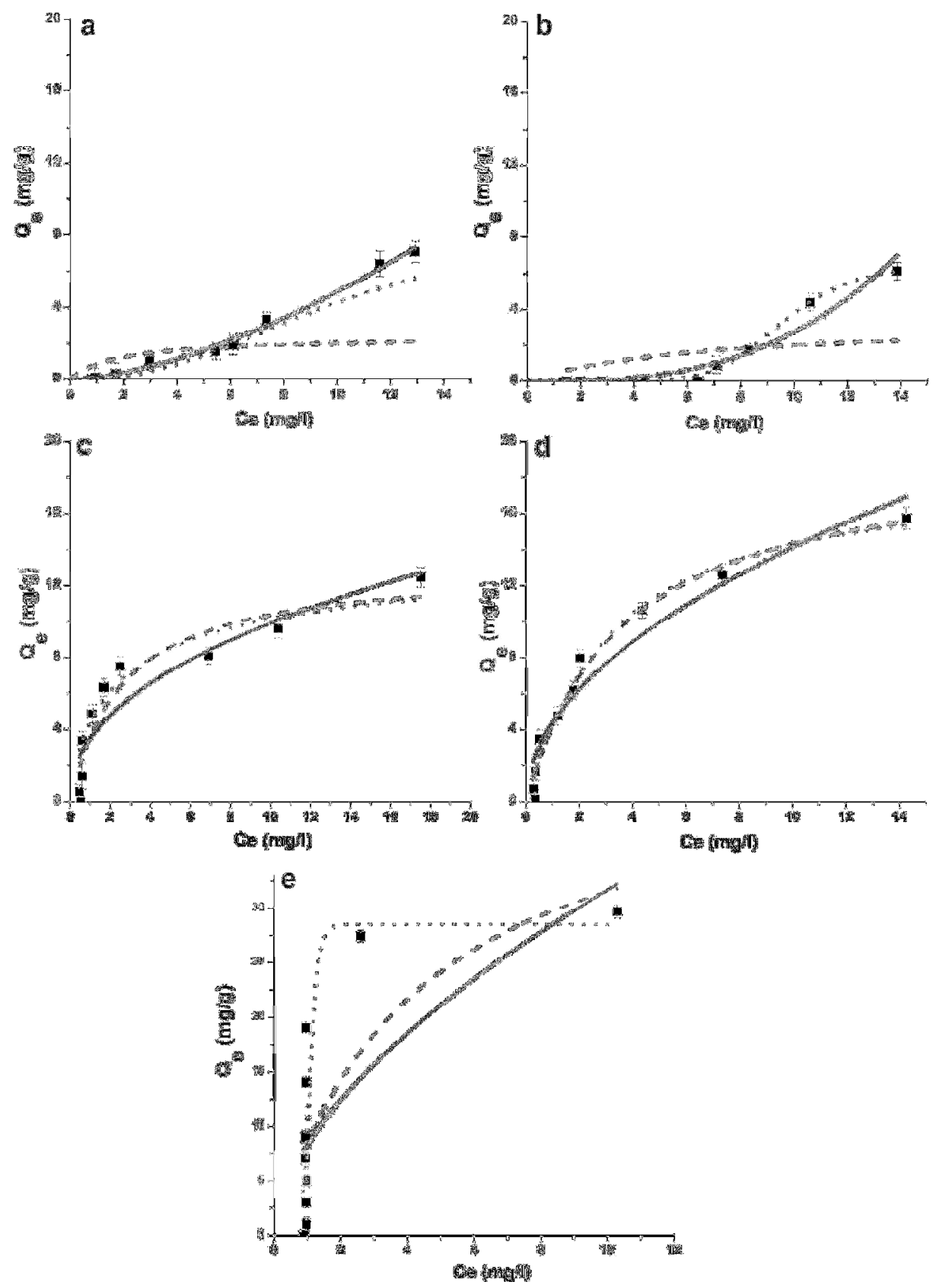

Figure 6: Adsorption isotherms for $\mathrm{MB}$ dye by $\mathrm{StPh}(\mathrm{a})$, milled $\mathrm{StPh}(\mathrm{b})$ and nanocomposites containing $1 \mathrm{wt} \%$ (c), 3 $\mathrm{wt} \%$ (d) and $5 \mathrm{wt} \%$ (e) MMT (the symbols represent the experimental values, and the lines show the calculated isotherms using the Freundlich (-), the Langmuir (---) and the Sips ( $\cdots$ ) models) 
NATALIYA E. KOCHKINA and NIKOLAY D. LUKIN

Table 3

Constants of isotherm models for methylene blue dye adsorption

\begin{tabular}{lccccc}
\hline Isotherm model & StPh & $\begin{array}{c}\text { StPh } \\
\text { milled }\end{array}$ & $\begin{array}{c}\mathrm{StPh} / \\
\text { MMT } 1 \%\end{array}$ & $\begin{array}{c}\mathrm{StPh} / \\
\text { MMT 3\% }\end{array}$ & $\begin{array}{c}\mathrm{StPh} / \\
\text { MMT 5\% }\end{array}$ \\
\hline Langmuir & & & & & \\
$a_{L}(\mathrm{~L} / \mathrm{mg})$ & 0.152 & 0.545 & 0.381 & 0.276 & 0.228 \\
$k_{L}(\mathrm{~L} / \mathrm{g})$ & 3.320 & 2.358 & 13.095 & 19.480 & 45.350 \\
$R^{2}$ & 0.238 & 0.130 & 0.880 & 0.975 & 0.535 \\
$\chi^{2}$ & 3.951 & 6.020 & 2.042 & 0.689 & 53.318 \\
Freundlich & & & & & \\
$K_{F}(\mathrm{mg} / \mathrm{g})$ & 0.007 & 0.125 & 3.532 & 4.384 & 8.257 \\
$l / n$ & 2.862 & 1.589 & 0.447 & 0.508 & 0.583 \\
$R^{2}$ & 0.941 & 0.988 & 0.829 & 0.927 & 0.477 \\
$\chi^{2}$ & 0.344 & 0.050 & 2.909 & 2.020 & 59.965 \\
Sips & & & & & \\
$Q_{m}(\mathrm{mg} / \mathrm{g})$ & 6.541 & 8.809 & 14.235 & 18.132 & 28.525 \\
$K_{S}(\mathrm{~L} / \mathrm{mg})$ & 0.001 & 0.003 & 0.453 & 0.386 & 0.493 \\
$l / n$ & 7.167 & 2.395 & 0.739 & 1.168 & 9.325 \\
$R^{2}$ & 0.995 & 0.891 & 0.987 & 0.998 & 0.713 \\
$\chi^{2}$ & 0.024 & 0.776 & 0.618 & 0.049 & 41.086 \\
\hline
\end{tabular}

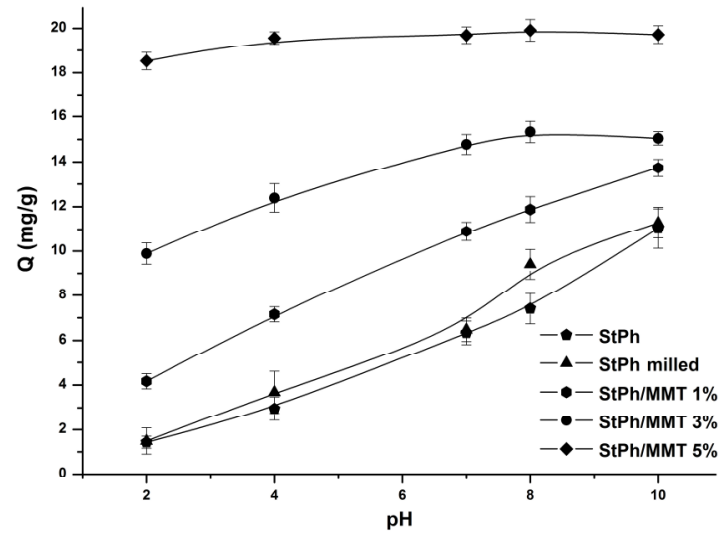

Figure 7: Effect of $\mathrm{pH}$ value on $\mathrm{MB}$ dye adsorption by the adsorbent samples tested in this work

\section{Reusability}

An important property of adsorbents is their reusability, which is one of the parameters determining the cost of the adsorption process. In this paper, the adsorption capacity of the nanocomposite sample with 5 wt\% MMT was investigated with repeated reuse in the process of methylene blue dye adsorption at the contact time of 40 minutes and the initial dye solution $\mathrm{pH}$. For this purpose, after its application in the adsorption, the nanocomposite sample was treated with $30 \mathrm{~mL}$ of $90 \mathrm{vol} \%$ ethanol aqueous solution for $180 \mathrm{~min}$ to remove the adsorbed dye. ${ }^{31}$ According to the results shown in Figure 8, the sample under study exhibited good adsorption ability after being used three times in a row.

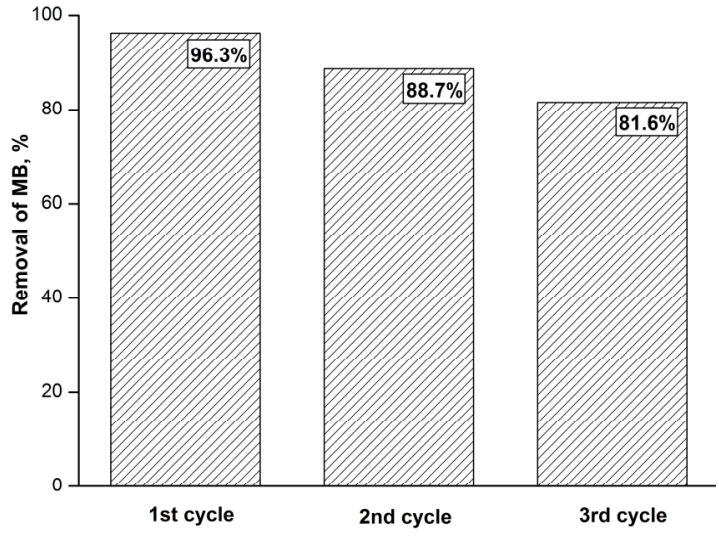

Figure 8: Reusability of the nanocomposite containing $5 \mathrm{wt} \% \mathrm{MMT}$

\section{CONCLUSION}

The results of this study demonstrate an effective method for producing novel eco-friendly nanocomposites based on StPh and MMT by mechanical treatment of their mixture in a laboratory-made vibration mill. The obtained nanocomposites had a larger surface area and more negative zeta potential values in comparison with these parameters for the initial and milled $\mathrm{StPh}$. The nanocomposites demonstrated better adsorption capacity towards MB and the material containing 5 wt $\%$ MMT showed the best efficiency in the dye removal. Furthermore, the adsorption capacity of the nanocomposite containing 5 wt $\%$ MMT was not significantly influenced by the $\mathrm{pH}$ value. The kinetic 
experiments showed that the adsorption process could be described by the pseudo-second-order model and the adsorption data correlated well with the three-parameter Sips model, indicating that the process represented monolayer adsorption on a heterogeneous surface. We can conclude that it is possible to use the $\mathrm{StPh} / \mathrm{MMT}$ nanocomposites as effective adsorbents for wastewater treatment.

ACKNOWLEDGEMENTS: The authors would like to thank the Upper Volga Region Centre of Physicochemical Research (Ivanovo, Russia) for some measurements carried out using their equipment.

\section{REFERENCES}

1 R. T. Yang, "Adsorbents: Fundamentals and Applications”, John Wiley \& Sons, Hoboken, 2003.

2 S. De Gisi, G. Lofrano, M. Grassi and M. Notarnicola, Sustain. Sci. Technol., 9, 10 (2016), https://doi.org/10.1016/j.susmat.2016.06.002

3 A. C. Bertolini (Ed.), "Starches: Characterization, Properties, and Applications", Taylor \& Francis, Boca Raton, 2010.

4 M. Haroon, L. Wang, H. Yu, N. M. Abbasi, Z. Abdin et al., RSC Adv., 6, 78264 (2016), 10.1039/C6RA16795K

5 R. Klimaviciute, J. Bendoraitiene, R. Rutkaite and A. Zemaitaitis, J. Hazard. Mater., 181, 624 (2010), doi: 10.1016/j.jhazmat.2010.05.058

6 L. Guo, G. Li, J. Liu, Y. Meng and G. Xing, J. Dispersion Sci. Technol., 33, 403 (2012), https://doi.org/10.1080/01932691.2011.567179

7 D. O. Krentz, C. Lohmann, S. Schwarz, S. Bratskaya, T. Liebert et al., Starch-Starke, 58, 161 (2006), https://doi.org/10.1002/star.200500431

8 P. F. Luckham and S. Rossi, Adv. Colloid Interface Sci., 82, 43 (1999).

9 V. A. Gerasin, E. M. Antipov, V. V. Karbushev, V. G. Kulichikhin, G. P. Karpacheva et al., Russ. Chem. Rev., 82, 303 (2013), http://dx.doi.org/10.1070/RC2013v082n04ABEH0043 22

10 G. Xing, Sh. Liu, Q. Xu and Q. Liu, Carbohyd. Polym., $\quad 87, \quad 1447 \quad$ (2012), https://doi.org/10.1016/j.carbpol.2011.09.038

11 Y. Koriche, M. Darder, P. Aranda, S. Semsari and E. Ruiz-Hitzky, Dalton Trans., 43, 10512 (2014), doi: $10.1039 / \mathrm{c} 4 \mathrm{dt} 00330 \mathrm{f}$
12 G. Xing, S. Liu, Y. Tang, H. Jiang and Q. Liu, Starch/Stärke, $\quad \mathbf{6 6}, \quad 824 \quad$ (2014), https://doi.org/10.1002/star.201300250

13 G. R. Mahdavinia, S. Hasanpour, L. Behrouzi and H. Sheykhloie, Starch/Stärke, 68, 188 (2016), https://doi.org/10.1002/star.201400255

14 L. Guo, Ch. Sun, G. Li, Ch. Liu and Ch. Ji, J. Hazard. Mater., 161, $510 \quad$ (2009), https://doi.org/10.1016/j.jhazmat.2008.04.003

15 M. A. Bhat, H. Chisti and Sh. A. Shah, Sep. Sci. Technol. 50, 1741 (2015) https://doi.org/10.1080/01496395.2014.978469

16 L. Guo, Sh. Zhang, B. Ju, J. Yang and X. Quan, J. Polym. Res., 13, 213 (2006), https://doi.org/10.1007/s10965-005-9028-4

17 C. Suryanarayana, Prog. Mater. Sci., 46, 1 (2001), https://doi.org/10.1016/S0079-6425(99)00010-9

18 H. Yan, X. Chen, Y. Feng, F. Xiang, J. Li et al., Polym. Bull., $\quad 73, \quad 1185 \quad$ (2016), https://doi.org/10.1007/s00289-015-1542-x

19 N. E. Kochkina, O. A. Skobeleva and Yu. V. Khokhlova, Part. Sci. Technol., 35, 259 (2017).

20 B. V. Pokid'ko, I. A. Tutorskii, V. V. Bitt, N.M. Sklyarevskaya and P. L. Zhuravleva, Colloid J., 71, 810

https://doi.org/10.1134/S1061933X09060106

(2009),

${ }_{21}$ G. Brindley and G. Brown, "Crystal Structure of Clay Minerals and their X-Ray Identification", Mineralogical Society, London, 1980.

22 P. Djomgoue and D. Njopwouo, J. Surf. Eng. Mater. Adv. Technol., 3, 275 (2013).

23 J. Madejová, Vib. Spectrosc., 31, 1 (2003), https://doi.org/10.1016/S0924-2031(02)00065-6

24 I. Capron, P. Robert, P. Colonna, M. Brogly and V. Planchot, Carbohyd. Polym., 68, 249 (2007), DOI: 10.1016/j.carbpol.2006.12.015

25 U. Heinze, D. Klemm, E. Unger and F. Pieschel, $\begin{array}{llll}\text { Starch/Stärke, } & \mathbf{5 5}, & 55 & \text { (2003), }\end{array}$ https://doi.org/10.1002/star.200390017

26 S. Lagergren, Kungliga Svenska Vetenskapsakademiens. Handlingar, 24, 1 (1898).

27 Y. S. Ho and G. Mckay, Can. J. Chem. Eng., 76, 822 (1998), https://doi.org/10.1002/cjce.5450760419

28 S. Rangabhashiyam, N. Anu, M. S. G. Nandagopal and N. Selvaraju, J. Environ. Chem. Eng., 2, 398 (2014), https://doi.org/10.1016/j.jece.2014.01.014

29 M. Petkovska, Adsorption, 20, 385 (2014), doi: 10.1007/s10450-013-9571-y

30 J. Bujdak, Appl. Clay Sci., 34, 58 (2006), https://doi.org/10.1016/j.clay.2006.02.011

31 J. He, A. Cui, Sh. Deng and J. P. Chen, J. Colloid Interface Sci., $\quad \mathbf{5 1 2}, \quad 190 \quad$ (2018), https://doi.org/10.1016/j.jcis.2017.09.106 